\title{
Recuerdos del Instituto de Investigaciones Estéticas $y$ de su revista Anales entre 1953 y 1980
}

Esta breve crónica sólo pretende destacar algunos aspectos y sucesos menores que tuvieron lugar entre los últimos años de la gestión de Manuel Toussaint, fallecido en 1955, y la de Jorge Alberto Manrique transcurrida de I974 a I980.

Ingresé al Instituto de Investigaciones Estéticas en 1953 gracias al generoso apoyo de Clementina Díaz y de Ovando, cuando aún cursaba la licenciatura en Historia en la Facultad de Filosofía y Letras. Había tomado entonces la decisión de especializarme en arte colonial, fascinada por las clases impartidas en el bachillerato por Francisco de la Maza, quien fue no sólo el gran especialista sino el mayor expositor del tema, tan famoso que su salón se abarrotaba de alumnos y personas ajenas al curso que iban sólo por el placer de escucharlo.

Consta en los Anales núm. 2I de 1953 el ingreso de Raúl Flores Guerrero, Carlos Villegas y yo al Instituto (es fácil imaginar la gran satisfacción que tuve al formar parte de esta institución), con lo cual el número de investigadores aumentó a Io. Para I964 ya éramos I 4 - con algunos cambios, entre ellos el fallecimiento del prometedor e inolvidable compañero Raúl—; en 1972, I2, y, gracias a la gestión de Jorge Alberto Manrique como director, los investigadores alcanzamos a ser 25 .

La publicación de los Anales se realizó de manera admirable desde 1937, demostrándose con ello la sabiduría y el compromiso intelectual que animaba a los fundadores. En poco tiempo la revista se convirtió, primero, en la única de su género en México, y pronto en la más importante de aquellos años para la difusión de la investigación y la historia del arte, con trascendencia en España, América Latina y poco después en los Estados Unidos. Los investigadores se comprometieron a entregar un artículo al año, sana costumbre que se cumplió durante mucho tiempo. 
Hoy día los Anales, emblema de nuestro Instituto, llegan al número ioo gracias al muy loable esfuerzo de Peter Krieger, quien ha sido el habilísimo coordinador durante los últimos io años, logrando con ello que la revista salga a la luz con la debida regularidad. Quede aquí una sincera felicitación para nuestro colega Peter.

En cuanto ingresé al Instituto, Manuel Toussaint me encomendó la clasificación de las diapositivas que estaban celosamente guardadas en una especie de ropero. A partir de esa tarea y de mi iniciativa de salir periódicamente a tomar fotografías para ilustrar los artículos y la docencia, se fue formando nuestra Fototeca.

Con mucha simpatía recuerdo las vívidas discusiones entre los maestros para definir las características formales de las obras de arte cuyas fotografías — muchas de ellas de piezas recién descubiertas - yo les mostraba.

Para colaborar en la clasificación de las mismas Manuel Toussaint contrató, aunque por corto tiempo, a un joven estudiante de secundaria que al paso de los años se convertiría nada menos que en el reconocido y sabio astrónomo Manuel Peimbert Sierra, Doctor Honoris Causa de la Universidad Nacional Autónoma de México.

Cuando el maestro Justino Fernández fue director del Instituto (I956I968), la Fototeca se instaló en un pequeño espacio independiente y se contrataron ayudantes. Más tarde, Clementina Díaz y de Ovando (directora de I968 a 1974) renovó considerablemente el equipo de cámaras y accesorios fotográficos, y a sugerencia mía, adquirió el Reprovit, estupendo aparato para la reprografía de documentos, el cual sigue prestando servicio. Durante su gestión, Jorge Alberto Manrique concedió más espacio a la Fototeca y por primera vez se reveló una fotografía en nuestro laboratorio. El trabajo lo realizó Rafael Rivera, estudiante de fotografía, quien me acompañó muchas veces a retratar monumentos religiosos y museos de la ciudad.

El entonces director comprendió que la Fototeca había crecido y que lo seguiría haciendo de manera importante, por lo que, con gran tino, decidió nombrar a una persona que la coordinara y así liberarme de esa responsabilidad, lo cual acepté con mucho gusto. La primera en ocupar el puesto fue mi alumna Amada Martínez.

Cuando el Instituto acababa de establecerse en Ciudad Universitaria, la planta de investigadores estaba compuesta por Manuel Toussaint, Manuel 
Romero de Terreros, Justino Fernández, Clementina Díaz y de Ovando, Francisco de la Maza, José Rojas Garcidueñas, Vicente T. Mendoza, Raúl Flores Guerrero, Carlos Villegas y yo.

Animaba la vida diaria del Instituto la encantadora personalidad de la secretaria del director, Luz Gorráez Arcaute, a quien quisimos todos de manera especial por el fino y genial humorismo del que hacía gala, el cual todos disfrutábamos tanto y aún recordamos con alegría. Es por ello que su nombre debe figurar en estas memorias.

Por su parte, Francisco de la Maza se preocupó por que los investigadores nos reuniéramos mensualmente para informar acerca de nuestros trabajos. Él quiso que estas juntas se llevaran a cabo el primer viernes de cada mes, costumbre que se ha mantenido. Pero, como con el paso de los años el número de investigadores aumentó, ya no fue posible presentar nuestros informes, por lo cual, como era de esperarse, las reuniones se convirtieron en sesiones académico-administrativas en las que se expone y se trata todo lo que interese para el mejor funcionamiento de la institución.

Las sesiones del Colegio de Investigadores se llevaban a cabo en nuestra Biblioteca, un lugar bastante reducido que prestaba distintos servicios, entre otros la reprografía de libros y documentos. Para entonces, el Instituto resultaba ya insuficiente, aunque todavía pasarían ocho años más hasta cambiarnos a nuestra sede actual.

Para terminar estas notas es indispensable mencionar la celebración del Primer Coloquio Internacional de Historia del Arte organizado por el Instituto de Investigaciones Estéticas bajo la dirección de Jorge Alberto Manrique, con el fin de festejar los 40 años de la institución. Desde 1939, según Clementina Díaz y de Ovando, el Instituto anhelaba organizar un coloquio internacional que no se logró entonces, pero que se hizo brillante realidad en 1975, en la ciudad de Zacatecas, con tema "La dicotomía entre arte culto y arte popular" sugerido por Ida Rodríguez Prampolini.

A partir de entonces el Instituto celebra dichos coloquios cada año y, como es de suponerse, con ello se promueve la difusión de sus trabajos académicos y se mantienen activas las relaciones profesionales con instituciones y colegas del extranjero, mismas que se nutren a través de la circulación de los Anales, por tanto aquí debe quedar asentada una cordial invitación a los investigadores del Instituto para que aumenten sus colaboraciones y así contribuyan al lucimiento de nuestra revista. 